\title{
'Marginal Employment': Stepping Stone or Dead End? Evaluating the German Experience*
}

\author{
Ronny Freier and Viktor Steiner**
}

'Marginal employment', i.e. employment with low working hours and earnings not covered by social security, has been gaining importance in the German economy over the past decade. Using a large newly available panel data set from the Employment Statistics of the Federal Employment Agency and statistical matching techniques, we analyse the effects of marginal employment on future individual outcome variables such as unemployment, regular employment and earnings. In addition to average treatment effects, we calculate dynamic and cumulative treatment effects accounting for total time spent in various labour market states and related earnings over a period of three years. We restrict the analysis to men and estimate the treatment effects separately for eastern and western Germany as well as for older workers and those workers who are likely to top up unemployment benefits with earnings from marginal employment. We find that marginal employment (i) does not affect time spent in regular employment within a three-year observation period, (ii) reduces future unemployment, where (iii) the effects on unemployment are to be seen as transitory. Furthermore, it (iv) slightly increases cumulated future earnings on average, and (v) is associated with a small negative cumulative earnings effect for older workers in western Germany.

\footnotetext{
* This paper was released for publication in May 2008.

** We thank one of the editors of this special issue and two anonymous referees for helpful comments. Moreover, we are grateful for comments on an earlier version of this paper by Florian Zinsmeister, Johannes Ziemendorff, Marco Caliendo, Andrea Weber, Kai-Uwe Mueller and seminar participants at the Stockholm School of Economics, the IAB Nuremberg, the Free University Berlin and the LoWER Workshop in Berlin. We would also like to thank the German Science Foundation (DFG) for funding under the project 'Work Incentives, Earnings-Related Subsidies, and Employment in Low-Wage Labour Markets' (Ste 681/5-1). The usual disclaimer applies.
}

\section{Contents}

1 Introduction

2 Institutional background

3 Data and evaluation design

$4 \quad$ Empirical methodology

5 Results

5.1 Propensity score matching

\subsection{Employment effects}

5.3 Earnings effects

6 Conclusion

References

Appendix 


\section{Introduction}

'Marginal employment' ('Geringfügige Beschäftigung'), i.e. employment with low working hours and earnings not or only partially subject to social security contributions, has been gaining importance in the German economy over the past decade. There are two opposing views on this development among economists and policy makers. On the one hand, the existence of marginal employment (ME) has been seen as a means to improve labour market flexibility, to shore up financial incentives to take up lowpaid work and to reduce labour costs for firms, thereby increasing the demand for low-productivity workers. This view seems to underlie recent development in 'active' labour market policy in Germany and elsewhere (see e.g. Fertig and Kluve 2006; Steiner 2006). On the other hand, critics are sceptical about the potential of marginal employment to enhance job creation and stress the danger of regular full-time jobs being substituted by subsidized ME (see e.g. Schöb and Weimann 2004: 115122; Bofinger et al. 2006).

Studying the labour market impact of ME may therefore shed light on the issue of labour market flexibility and is also of substantial policy interest. For various reasons, the German case is particularly interesting: firstly, while social security contributions weigh relatively heavily on low-productivity jobs, $\mathrm{ME}$ is partly exempted from this burden in Germany. Secondly, ME has grown substantially in Germany over the last couple of years, while overall employment has stagnated in this period. Thirdly, marginal employment has gained considerable importance in German labour market policy. While a reform in 1999 tried to curb the expansion of ME, the so-called 'Mini jobs' reform in 2003 was implemented with the aim of increasing work incentives in the low-wage sector of the economy (see e.g. Steiner and Wrohlich 2005). Recently, the employers' contribution rate on these jobs has been increased from $25 \%$ to $30.1 \%$ to again curb the alleged substitution of full-time jobs by publicly subsidised ME.

Despite its increasing quantitative importance and policy relevance, there has been relatively little empirical research on the labour market effects of ME for Germany. There are some studies describing the recent evolution and structure of ME in the German labour market (see e.g. Schupp and Birkner 2004; Fertig and Kluve 2006). Also, the labour supply effects of the mentioned 'Mini jobs' reform have been analysed on the basis of ex-ante simulation studies (Arntz et al. 2003; Steiner and Wrohlich 2005) as well as ex-post evaluations (Caliendo and Wrohlich
2006). These studies found that the reform has only very small labour supply effects, especially among the target group of long-term unemployed people. However, to the best of our knowledge there has hitherto been no empirical investigation on whether ME acts as a 'stepping stone' to regular employment or instead leads to 'dead end' jobs. In a recent study for Austria, Böheim and Weber (2006) find that unemployed people who take up ME end up with less regular employment, more unemployment and lower wages after three years than the control group of unemployed who do not enter ME. These results seem to support the 'dead end' view and the critics of publicly subsidised ME. ${ }^{1}$

This paper provides an empirical analysis of the employment and earnings effects of ME for Germany. The empirical analysis is based on a statistical matching approach making use of register data from the Employment Statistics of the Federal Employment Agency. We restrict the analysis to men because including women would make it necessary to analyse the interrelations between $\mathrm{ME}$ and (conventional) part-time employment. As shown by Freier and Steiner (2007), these two employment types are substitutes in production, especially for women whose part-time share amounts to more than a third of total employment in Germany. Furthermore, the labour supply of married women would make it necessary to account for household characteristics, such as number and age of children, earnings of the spouse, and other household income, on which we do not have information in our data. The analysis distinguishes between eastern and western Germany because of prevailing pronounced differences in unemployment between the two regions. We would expect ME to be more effective as a stepping stone into regular employment in labour markets with lower unemployment as it is the case, on average, in western Germany. Furthermore, we also present results for older men, because, for institutional reasons, we expect that the effects of ME on future employment and earnings may differ by age and because older unemployed people have recently become a special target group for labour market policy (see Haan and Steiner 2006).

In the next section, we provide some institutional background on ME in Germany. Our data and evaluation methodology are described in sections 3 and 4. The evaluation results, summarised in section 5 show that although ME does not increase time spent

\footnotetext{
${ }^{1}$ Whereas the 'stepping stone' hypothesis in relation to temporary jobs has been analysed frequently in the literature (for a recent survey, see Ichino et al. 2006), there are apparently no studies focusing on ME for other countries.
} 
in regular employment within a three-year observation period it reduces future unemployment and, on average, slightly increases cumulated future earnings. We also identify important age differences in these effects. Section 6 summarises the main results of the study and concludes.

\section{Institutional background}

Since the mid 1990s, ME has been increasing substantially in Germany. Depending on how ME is measured, estimates for recent years vary between 3 and 6 million people in ME, with a significant increase over time (see e.g. Schupp et al. 1998; Rudolph 1998; Schupp and Birkner 2004; Ziemendorff 2006). In particular, there is the important distinction between ME held as the only job or as a secondary job. On the basis of data from the German Socioeconomic Panel (SOEP), Schupp and Birkner (2004, Table 4) estimate the total number of jobs in ME ('Mini jobs') at about 5 million in 2003, of which 3.6 million were held as the only job, with an increase of about half a million since 2000, according to their estimates. Also using SOEP data, Rudolph (1998) documents a substantial increase in ME since the beginning of the 1990s.

This development was accompanied by several policy reforms aimed at either restricting or strengthening financial incentives for ME. Before 1999, jobs with an upper earnings threshold of 325 Euros per month and a maximum of 15 weekly working hours were exempted from social security contributions (SSC) on the part of the employee. The employer had to pay a 20 percent tax on gross wages. ME in a secondary job was treated equally with respect to SSC. Earnings from several ME jobs held by a single person were added up and the resulting sum was subject to SSC.

The political aim of the 1999 reform was to restrict the expansion of ME. Since then, the employer has had to pay $22 \%$ SSC. Thus, little changed under this reform for the employers of individuals working in ME. The reform did not improve financial incentives for those workers to expand hours of work and take up regular employment either. Since SSC, and possibly also income taxes, had to be paid in full above the relatively low SSC threshold, the marginal tax rate on such jobs remained rather high. On the other hand, ME could be financially attractive for recipients of unemployment benefit up to an earnings threshold of 165 Euros, beyond which the deduction rate became $100 \%$.

In contrast to the previous reform, the 'Mini jobs Reform' of 2003 was intended to improve incentives to take up ME. The restriction on maximum hours was abolished and the upper threshold of exempted earnings was raised to 400 Euros per month. Moreover, earnings between 401 and 800 Euros are now subject to a modified SSC scheme. Although this reform improved financial incentives for 'secondary workers' (housewives, students, pensioners) to take up low-paid jobs, it hardly changed incentives for persons receiving unemployment or social assistance benefits because of the high deduction rates (for details see e.g. Steiner and Wrohlich 2005; Steiner 2006). Motivated by the strong expansion of ME following the 2003 reform, the employers' SSC rate was increased from $25 \%$ of gross monthly earnings of 400 Euros to $30.1 \%$ in July 2006. For part-time jobs with earnings between 401 and 800 Euros, employers still pay the normal employers' SSC rate of currently about $20 \%$.

\section{Data and evaluation design}

Given the focus of our paper, the following analysis is restricted to ME held as the only job and refers to men entering registered unemployment after the introduction of the 1999 reform and before the 2003 reform became effective. Thus, our sample excludes all employed persons with ME held as a secondary job as well as people out-of-the-labour force, such as pensioners and students. For the reasons mentioned in the Introduction, we restrict the analysis to men.

The data for our empirical analysis are derived from the Employment Panel of the Federal Employment Agency (EP-FEA), see Meinken and Koch (2005). The EP-FEA contains detailed quarterly information on employment and wages for a $2 \%$ random sub-sample of all employees subject to social security for the period 1998-2005, amounting to about 600,000 observations per quarter. Due to the fact that ME had to be notified to the social security system from 1999, the data include information on ME starting with the second quarter of that year. Spell information refers to a person's main labour force status. The evolution of marginal employment in eastern and western Germany within the observation period as derived from our EP-FEA data is shown in Figure 1.

The main strength of the EP-FEA data set is its large size and the correspondence of what is coded as $\mathrm{ME}$ in the data to the legal definition. We can, therefore, explicitly distinguish ME from other forms of employment, most importantly from con- 


\section{Figure 1 \\ Men in marginal employment as a share of labour force by region, in quarters, 1999-2003}

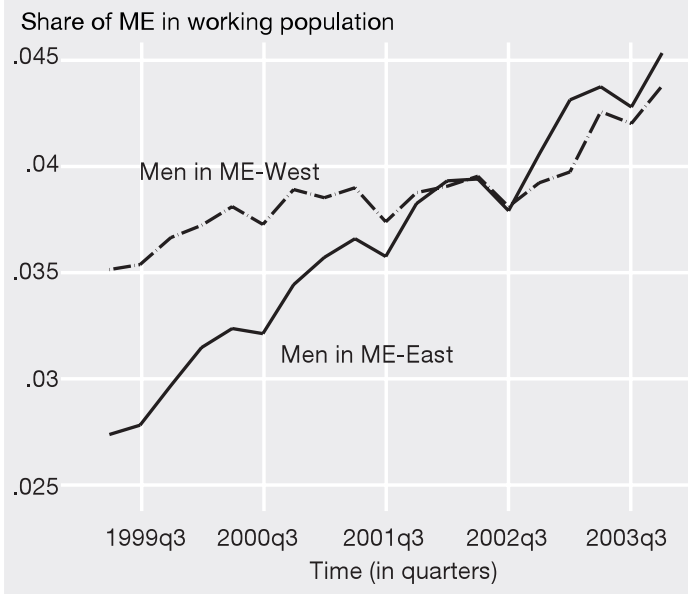

Source: Own calculations based on the EP-FEA data.

ventional part-time employment. ${ }^{2}$ Another main advantage is the high quality of employment-spell (measured in days) and wage information in the EPFEA due to the fact that this information is used for the calculation of individual entitlements to state pensions.

There are also a few shortcomings of the EP-FEA data: drawing on employment register data, unem-

${ }^{2}$ For data after the second quarter of 2003, the FEA also provides supplements to the main data which contain information on $\mathrm{ME}$ as a secondary job. ployment was initially not registered in the EP-FEA data. In 2000, the FEA started to supplement the data with information from the unemployment statistics. However, unemployment remains incompletely coded in the data, as neither unemployment not registered at the labour agency ${ }^{3}$ nor unemployment during a spell of ME is coded. Moreover, there is no information on the amount of unemployment benefit received by a person in the data. Another disadvantage of the EP-FEA data is that the data do not contain information on household variables such as the employment status of the spouse, the presence of children and other household income. Since we restrict the analysis to men whose employment behaviour is not expected to depend significantly on these variables, this is of little concern here.

In order to evaluate the effects of ME on subsequent individual labour market outcomes, we have organized the EP-FEA data as illustrated in Figure 2. The analysis is based on a sample of four quarterly inflow cohorts of men who became unemployed for at least 3 months during the period from April 1, 2001 to March 31, 2002 and who were either in regular employment or in ME before. We distinguish between quarterly inflow cohorts to account for potential seasonal and business-cycle effects on individual labour market outcomes. ${ }^{4}$ There are two reasons for including only those who have been unemployed for at least 3 months in the analysis: first, shorter spells

\footnotetext{
${ }^{3}$ Note that in Germany a person is registered as unemployed without beeing entitled to unemployment benefits if he proves to the employment agency that she is actively looking for a job. ${ }^{4}$ The German business cycle turned from a modest downturn into a mild recession during the inflow period.
}

\section{Figure 2}

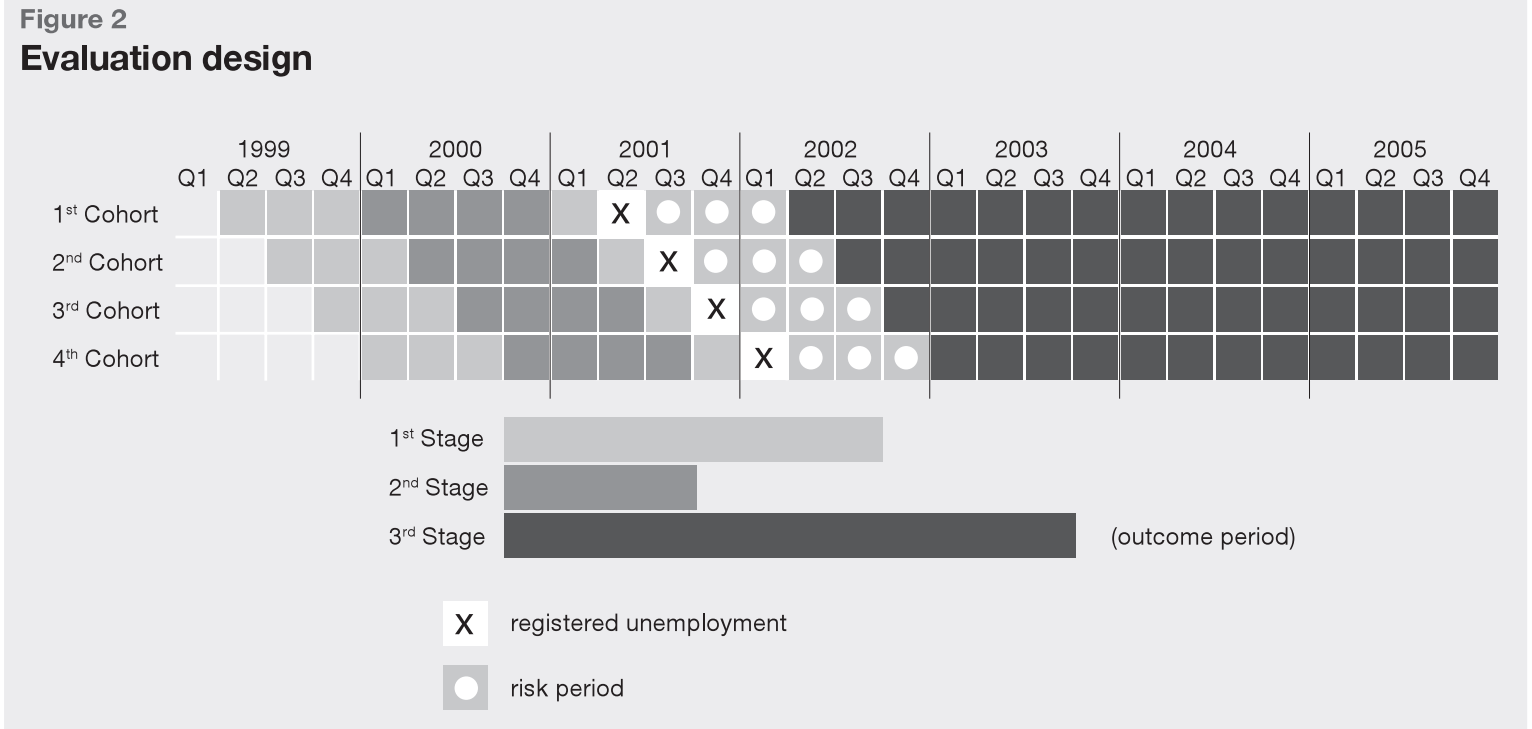


Table 1

Sample description

\begin{tabular}{|l|c|c|c|c}
\hline \multirow{2}{*}{} & \multicolumn{2}{|c|}{ Western Germany } & \multicolumn{2}{c}{ Eastern Germany } \\
\cline { 2 - 5 } & Pot. controls & Treated & Pot. controls & Treated \\
\hline Number of observations & 20763 & 1275 & 10059 & 908 \\
\hline Cohorts & \multicolumn{3}{|c}{} \\
\hline Cohort 1 & 4058 & 261 & 1976 & 165 \\
\hline Cohort 2 & 4486 & 308 & 2215 & 211 \\
\hline Cohort 3 & 6411 & 412 & 2909 & 273 \\
\hline Cohort 4 & 5808 & 294 & 2959 & 259 \\
\hline Number of obs. (50+yrs.) & 3285 & 243 & 1981 & 202 \\
\hline Number of obs. (<166 Euro) & 20763 & 577 & 10059 & 648 \\
\hline
\end{tabular}

Note: For the definition of the potential control group, see text.

Source: Own calculations based on EP-FEA data.

of unemployment are not identified in our data. Second, even if they were, we would prefer to restrict the analysis to longer unemployment spells because the analysis appears more relevant for longer-term unemployment than for purely frictional unemployment.

For each person included in the sample, we define a 'risk period' of 9 months and determine whether the individual took up ME within this period as the first occupational status after leaving unemployment. Following terminology in the evaluation literature, we denote these persons as belonging to the 'treatment group'.5 Individuals who remained unemployed or found positions in regular employment within the risk period comprise the potential control group. Note that, contrary to what seems to be usual the practice in the evaluation literature, we neither exclude individuals from the control group altogether nor treat them as right-censored at the time when they change treatment status. The reason for this is that we want to assess the future labour market performance of men who take up ME within a specific time period - the risk period defined above - compared to a control group of people who had the same ex-ante chance of taking up ME within this risk period. However, to appraise the sensitivity of our results to this specification, we also estimate treatment effects leaving out all of the individuals from the control group who changed treatment status during the outcome period.

\footnotetext{
5 As suggested by one referee, the term 'treatment' as usually used in the evaluation literature refers to a (training) programme which is formally initiated by a third party (the employment agency). Although we agree that the degree to which unemployed people and/or the employment agency decide on programme participation in a specific programme may differ, the decision to participate is ultimately voluntary-no one can be forced to participate in a programme, of course, although there might be conse-
}

Table 1 shows that there is a total of 33,005 observations of which 1,275 (908) are treated and 20,763 $(10,059)$ belong to the potential control group in western (eastern) Germany. The number of observations is not distributed evenly across the four cohorts, which may reflect both seasonal and cyclical effects. In each of the four cohorts, the share of unemployed men taking up ME in eastern Germany is much larger than that in the west, with an average share across cohorts of about $9 \%$ and $6 \%$ respectively. This may be related to the much higher unemployment rate and poor prospects regarding regular employment in eastern Germany, also reflected by the high share of the total unemployment inflow in eastern Germany relative to Germany as a whole. ${ }^{6}$

The lower part of Table 1 shows the distribution of observations for men older than 50 and for those with monthly earnings of less than 166 Euros. Below, we present separate estimation results for older men to check whether ME may act as a stepping stone into regular employment also for older people whose share of long-term unemployment is disproportionally high in both eastern and western Germany. We also estimate separate treatment effects for ME with monthly earnings of less than 166 Euros to check whether they differ from those ob-

quences for refusal to participate, such as loss of unemployment benefits. Benefit sanctions can also be imposed by the employment agency, however, if the unemployed does not actively search for a job (see e.g. Müller 2007), which could perhaps be avoided by taking up marginal employment. Thus, the perceived difference between traditional active labor market programmes, such as training courses or public works programmes, may be more semantic than substantial regarding the participation decision. In any case, given that the Conditional Independence Assumption discussed in Section 4 holds, this distinction is of no relevance.

${ }^{6}$ The eastern German share of $1 / 3$ of the total unemployment inflow is almost double its population share. 
Table 2

Descriptive statistics for outcome variables

\begin{tabular}{|l|r|r|r|r|r|r|r|r|}
\hline \multirow{2}{*}{} & \multicolumn{4}{|c|}{ Western Germany } & \multicolumn{3}{c|}{ Eastern Germany } \\
\cline { 2 - 9 } & \multicolumn{2}{|c|}{ Pot. controls } & \multicolumn{1}{c|}{ Treated } & \multicolumn{2}{c|}{ Pot. controls } & \multicolumn{2}{c|}{ Treated } \\
\cline { 2 - 9 } & \multicolumn{1}{|c|}{ Mean } & \multicolumn{1}{c|}{ Std } & \multicolumn{1}{c|}{ Mean } & \multicolumn{1}{c|}{ Std } & Mean & \multicolumn{1}{c|}{ Std } & \multicolumn{1}{c|}{ Mean } & \multicolumn{1}{c|}{ Std } \\
\hline Days in regular employment & 154.68 & 137.46 & 119.63 & 125.81 & 145.75 & 130.97 & 132.26 & 121.56 \\
\hline Days in ME & 19.69 & 57.12 & 116.19 & 126.39 & 18.07 & 52.39 & 95.23 & 115.69 \\
\hline Days in ME (<166 Euros) & 9.59 & 33.88 & 51.93 & 86.95 & 11.73 & 39.07 & 62.76 & 93.79 \\
\hline Days in unemployment & 190.24 & 135.59 & 128.21 & 116.19 & 200.58 & 130.81 & 135.64 & 114.08 \\
\hline Wage (during employment) & 1657.63 & 935.25 & 882.87 & 757.59 & 1306.70 & 698.85 & 857.30 & 619.60 \\
\hline
\end{tabular}

Note: For the definition of the potential control group, see text.

Source: Own calculations based on EP-FEA 1998-2005.

tained for the treatment group as a whole. As mentioned in Section 2, in the observation period the maximum amount that a recipient of unemployment benefit could earn was 165 Euros per month (earnings above this threshold were deducted at a rate of $100 \%)$. One might therefore expect that people earning less than this threshold are just topping up unemployment benefits and ME in this case should be evaluated differently than in cases where ME is associated with earnings above this threshold. In fact, Table 1 shows a large share of ME below this threshold: about $45 \%$ in western Germany and more than $70 \%$ in eastern Germany. Since there is no direct information in our data about whether an individual still receives unemployment benefit while in $\mathrm{ME}$, we can only distinguish indirectly between ME undertaken as a means of topping up unemployment benefit and 'pure' ME by using information on the corresponding amount of earnings.

Our choice of the inflow sample is motivated by the requirement for sufficiently long observation periods before and after the risk period. The choice of the risk period, in turn, takes into account that during the first few months of unemployment people tend to search for regular employment or do not search for a job at all, and may only later lower their aspiration levels and take up ME. Furthermore, the pressure from the employment office to take up ME might also increase with the duration of unemployment. By choosing a 9-month risk period we take these effects into account and, at the same time, leave a sufficiently long time period for evaluating the longer-term effects of taking up ME.

To evaluate the labour market effects of ME, we define several outcome variables over a period of a minimum of 3 years (subsequently denoted as 'outcome period') after the risk period ends (Stage 3, see Figure 2). For each cohort, the end of the risk period is set before the beginning of 2003 to avoid interference from the 'Mini job' reform implemented in April 2003 (see Section 2) and anticipatory effects in the first quarter of that year. The chosen length of the outcome period allows us to study longer-term (dynamic) effects of participating in $\mathrm{ME}$ on labour market outcomes. The outcome variables of interest are: (i) time spent in regular full-time employment, (ii) in ME, (iii) in registered unemployment, and (iv) wages.

Table 2 shows that, both in western and eastern Germany, previously unemployed men who took up ME within the risk period (treatment group) spent less time in regular employment during the outcome period than those who did not take up ME within the risk period (unmatched control group), but also spent much less time in unemployment. On average, the treatment group was in ME for 116 (95) days in western (eastern) Germany. In accordance with our definition given above, we also measure the time spent in ME for the control group. Compared to ME overall, the average number of days in ME with monthly earnings below 166 Euros is much lower for the treatment group both in western and eastern Germany. This may suggest that the use of ME to top up unemployment benefit is used as a temporary rather than a permanent option. Almost by definition, the average monthly wage in employment is much lower in the treatment group than in the unmatched control group, although this difference is less pronounced in eastern Germany. Monthly earnings coded in the EP-FEA data are derived from information on daily earnings and employment days. ${ }^{7}$

Of course, these differences in the outcome variables between the potential (unmatched) control

\footnotetext{
${ }^{7}$ If a worker was employed for less than 30 days within a month,
} his wage is adjusted to correspond to a full employment month. 
and the treatment group do not represent the effect of taking up $\mathrm{ME}$ on future labour market outcomes because the two groups are likely to differ in various characteristics affecting both selection into $\mathrm{ME}$ and the respective outcome variable. In the next section, we present our approach to account for potential selection effects in the estimation of treatment effects.

\section{Empirical methodology}

We want to estimate the average effect of taking up $\mathrm{ME}$ in the group of previously unemployed people who actually took up ME instead of remaining unemployed and continued searching for a regular job. This effect, which is the focus of much of the recent evaluation literature (see e.g. Heckman, LaLonde and Smith 1999), is termed the 'average treatment effect on the treated, ATT. It is defined as $\operatorname{ATT}(X)=E\left(Y_{1}-Y_{0} \mid D=1, X\right)$, where $Y_{1}$ is the potential outcome if the individual with observable characteristics $X$ takes up ME $(D=1), Y_{0}$ is the potential outcome if the individual does not self-select into $\operatorname{ME}(D=0)$, and $E$ is the mathematical expectation operator. By simple averaging, the ATT for a sub-sample or the whole sample of participants can be derived, e.g. for the latter $A T T=$ $E_{X}\left[E\left(Y_{1}-Y_{0} \mid D=1, X\right)\right]=E_{X}[(E(Y \mid D=1, X)-$ $E(Y \mid D=0, X)) \mid D=1]$.

The evaluation literature offers various ways to estimate the ATT. The traditional control function approach (see e.g. Heckman and Robb 1985; Heckman, LaLonde and Smith 1999: 1956-1961) specifies an outcome and a selection equation in terms of a latent and an observed indicator variable which both depend on observed and unobserved characteristics. This approach can also be adapted to take into account the dynamic nature of treatment assignment and outcomes by way of duration models. A possible drawback of the control function approach is that it relies heavily on functional form assumptions and usually also on some exclusion restrictions for identification. ${ }^{8}$ Ignoring 'selection on

\footnotetext{
${ }^{8}$ For applications to the evaluation of training programmes in Germany see e.g. Hujer et al. (1997) and Kraus et al. (1999). In the more recent 'timing-of-events' approach developed by Abbring and Van den Berg (2003) the ATT is identified from the sequence of assignment to a programme and the event defining the outcome variable (e.g. unemployment-to-employment transition) without exclusion restrictions on the set of observables included in the equation describing the outcome variable. Since our sample design allows for multiple ME spells, change in treatment status as well as several outcome variables (including wages), the joint estimation of a fully specified (multiple-state, multiple spell) hazard rate model and wage equation does not seem feasible and is certainly beyond the scope of this paper. Furthermore, even if it could be done, we doubt that it would add substantial insights to answering our research question specified above.
}

unobservables', the ATT can also be estimated using an extended matching estimator that can account for the dynamic nature of treatment assignment and outcomes (see e.g. Gerfin and Lechner 2002; Sianesi 2004; Fitzenberger et al. 2006). ${ }^{9}$

Here we follow these latter authors and apply propensity-score matching to estimate the ATT of taking up ME for the outcome variables defined in the previous section. Statistical matching is based on variants of the Conditional Independence Assumption (CIA) which states that, conditional on $X$, the potential outcomes are independent of participation in the programme. Since we are estimating the ATT, we only need to assume that $Y_{0}$ is independent of $D$, because the moments of the distribution of $Y_{1}$ for the treatment group can be estimated directly. In fact, for the purpose of estimating the ATT we can even rely on the less restrictive assumption that the conditional mean of the outcome variable is independent of the treatment status, i.e. $E\left(Y_{0} \mid D=\right.$ $0, X)=E\left(Y_{0} \mid D=1, X\right)=E\left(Y_{0} \mid X\right)$. In other words, selection into ME only depends on observables $X$, but does not depend on unobservable factors.

This is obviously a rather strong assumption whose credibility might be questioned. However, for the following reasons we believe that this assumption is likely to hold for our application: firstly, we condition on both an individual's employment status in the quarter before entering unemployment and restrict the analysis to unemployed people who experience an unemployment spell lasting for at least 3 months. Whilst this restriction puts limits on the generality of our analysis, it also reduces potential differences in unobserved heterogeneity affecting both treatment status and outcome variables, such as the motivation to search for a job. Secondly, we match both on labour market outcomes from 2 years prior to the treatment as well as the duration of the current unemployment spell. We believe that this further reduces differences in unobserved heterogeneity affecting both treatment status and outcome variables. And thirdly, we show that our matching procedure is very successful in balancing the differ-

\footnotetext{
${ }^{9}$ All these approaches evaluate programme effects on the respective outcome variable within the observed outcome period. As suggested by one referee, one could also attempt to simulate the effect of the programme on the equilibrium distribution of labour market outcomes (states). This would, however, require the specification and estimation of a fully specified multiple state, multiple spell hazard rate model and imply out-of-sample predictions. Although this more general approach would make it possible to answer additional policy-relevant questions and also to perform ex-ante evaluations of potential policy reforms, it is not required to analyse the research questions usually posed in the ex-post programme evaluation literature.
} 
ences in observable characteristics between the treatment and control group.

In particular, we match on indicators of an individual's previous labour market history as well as the elapsed duration in the current unemployment spell before entering ME. Conditioning on previous unemployment should be a rather effective way to control for time-invariant unobserved individual effects, as suggested by previous labour market research for Germany (see e.g. Lechner 1999; Caliendo and Kopeinig 2008). Conditional on the validity of the CIA assumption, the ATT can be estimated consistently simply by taking the mean over the difference of each participant (or a sub-group of participants defined by the respective partitioning of $X$ ) and some weighted control group of non-participants, i.e.:

$$
A T T=\frac{1}{N_{1}} \sum_{i=1}^{N_{1}}\left(Y_{1 i}-\sum_{j=1}^{N_{0}} \omega(i, j) Y_{0 j}\right)
$$

where $N_{1}\left(N_{0}\right)$ is the number of participants (nonparticipants) and $(i, j)$ is a weight placed on the $j$-th individual from the control group of non-participants in constructing the counterfactual for the $i$-th individual of the treatment group. Matching estimators differ in the choice of the weighting function (see e.g. Heckman, Ichimura, Smith, and Todd 1998). Here, we apply a two-step matching estimator: ${ }^{10}$

In the first step, we match on all variables defined at the time when the individual entered unemployment using a combination of nearest neighbour and caliper matching. In particular, for each treated person $i$ we identify six individuals (with replacement) in the control group for whom the estimated propensity score is nearest to that of person $i$. Of those individuals we only keep the ones whose propensity score lies within a radius of 0.005 , which guarantees satisfactory matching quality, especially at the tails of the distribution of propensity scores. ${ }^{11}$

In the second step, we match directly on the elapsed duration in unemployment before ME is taken up

\footnotetext{
${ }^{10}$ Alternative ways to match on variables varying over the outcome period are presented in e.g. Lechner (1999) and Sianesi (2004).

${ }^{11}$ Instead of the fixed radius 0.005 we have alternatively used estimated standard errors of propensity scores $(0.0489$ for the western German, 0.0495 for the eastern German sample) to define the radius. Although these exceed our fixed radius by the factor 10 , this had very little effect on the point estimates and the estimated standard errors due to the fact that for the majority of the observations the six nearest neighbour condition is binding. For example, the point estimate for the outcome variable unemployment in western Germany (all treated persons) changed from -89.72 to -89.86 , and in eastern Germany from 80.55 to 80.47 .
}

within the risk period. It is, of course, crucial to match on this variable to avoid comparing a treated person who takes up ME after an elapsed unemployment duration of, say, 9 months with a person from the potential control group with only 3 months of elapsed unemployment duration. Since it varies with process time, this variable cannot be used in the first step of the matching procedure. Given that a minimum of 3 months of unemployment is required for inclusion in our sample and our definition of the risk period, we define the following unemployment duration categories: one quarter, two quarters or three quarters of elapsed unemployment duration. Then, for each person in the treatment group with a given elapsed duration of unemployment at the time of taking up ME we select those individuals from the pool of up to six potential controls with a similar elapsed duration of unemployment. So, for example, a treated person with an elapsed unemployment duration of, say, 2 quarters is only matched to members of the potential control group with at least 2 quarters of unemployment. If no match is found among the group of up to six potential candidates, we match the treated person to controls from the nearest duration category. The chosen number of six nearest neighbours guarantees both a sufficient number of individuals to allow for exact matches in the second step and a high matching quality, as shown below.

For statistical matching to work, it is crucial to condition on those variables expected to affect both an individual's treatment status and his labour market outcomes. In German labour market studies, it is generally considered to be especially important to include indicators of an individual's previous (un)employment history in the set of matching variables (see e.g. Lechner 1999; Caliendo and Kopeinig 2008). Given the chosen inflow period, we observe how much time (in days) an individual spent in regular employment, in ME or out-of-the-labour force during a period of 2 full years before entering unemployment (Stage 1, see Figure 2 in the previous section). Since information on registered unemployment is added only after 1999 and we require that an individual in the sample must have been in some form of employment immediately before entering the unemployment spell, we have one full year (Stage 2) during which we can compute individual durations in unemployment.

In addition to indicators of an individual's previous employment history, we match on a large number of other individual characteristics dated at the time of entry into unemployment. These include an individual's age, his previous wage, the 
level of education, ${ }^{12}$ nationality, previous occupational status, size and industry classification of the last firm, and the quarter of an individual's entry into unemployment. Table A1 in the Appendix contains descriptive statistics on all matching variables for, respectively, the treatment and the potential control groups in the two regions. The table shows large differences between the sample means of most variables in the treatment and the potential control group before matching on observable characteristics. For example, the average wage in western Germany earned by the treatment group before entering unemployment is about 430 Euros less than among the potential controls, whereas the share of time spent in ME by the former is $12.2 \%$ compared to only $3.7 \%$ in the latter group.

\section{Results}

\subsection{Propensity score matching}

The estimation results for the probit models used to calculate the propensity scores for matching potential controls to treated individuals are contained in Table A2 in the Appendix. We have estimated these probits for the total eastern and western German samples and also for the restricted samples including only those observations in the treatment group with monthly earnings of less than 166 Euros. The same set of matching variables is included in all models. To allow for age differences in selection into ME we include interaction terms of an age dummy (age 50+) and some of the matching variables. As expected, age, indicators of an individual's previous (un)employment history and some of the interaction terms between age and some of these indicator variables have significant and strong effects on selection into ME.

To test if our matching procedure balances the distribution of matching variables between the treatment and the control group, we use the standardized bias (SB) measure suggested by Rosenbaum and Rubin (1985). For each matching variable the SB is defined as the difference of the sample means in the treated and matched control sub-samples as a percentage of the square root of the average of sample variances in both groups, i.e.:

\footnotetext{
12 As the EP-FEA has a rather large share of observations with missing information on educational attainment, we have used the panel structure of the data to impute information on education from earlier or later observations of the same person. Observations with missings in the education variable for which we could not impute valid values in this way are given a 'missing' dummy variable as the education category in the probit estimation of propensity scores below.
}

$$
S B=100 \cdot \frac{\overline{X_{1}}-\overline{X_{0}}}{\sqrt{0.5\left(V_{1}(X)+V_{0}(X)\right)}}
$$

In addition, we have also calculated conventional ttests for equality of the means in two independent samples (assuming equal population variances) for each matching variable. As shown in Table 3, only in one case does the t-test exceed the critical value of about 2 (at the $5 \%$ significance level, two-sided test) after matching. This is of little concern, however, since the coefficient of the variable in question ('skilled' in eastern Germany) is not statistically significant in the probit equation (see Table A2 in the Appendix). That the matching procedure is fairly successful in balancing the two groups in terms of observable characteristics is also suggested by the before-after comparison of the SB measure, which shows a substantial reduction for almost all matching variables.

Following usual practice (see e.g. Caliendo and Kopeinig 2008), we estimate treatment effects only for those individuals for whom we have identified controls with similar propensity scores or, in the language of the matching literature, for observations in the two groups with 'common support' regarding the propensity score. As indicated by the box-plots of the distribution of the estimated propensity scores in Figure A1, the overlap between the two groups is quite good in general, with the exception of some treated persons with very high scores. However, only very few observations had to be dropped because no suitable matched controls could be found, which had no effect on estimation results. 
Table 3

\section{Standardised bias and t-test}

\begin{tabular}{|c|c|c|c|c|c|c|c|c|}
\hline & \multicolumn{4}{|c|}{ Western Germany } & \multicolumn{4}{|c|}{ Eastern Germany } \\
\hline & \multicolumn{2}{|c|}{ SB } & \multicolumn{2}{|c|}{ t-test } & \multicolumn{2}{|c|}{ SB } & \multicolumn{2}{|c|}{ t-test } \\
\hline & Before & After & Before & After & Before & After & Before & After \\
\hline $30<$ Age $<50$ & 4.8 & 2.6 & 4.90 & 0.82 & 6.7 & 3.0 & 4.70 & 0.78 \\
\hline Age $>49$ & 8.2 & 0.6 & 8.31 & 0.2 & 6.2 & -2.4 & 4.38 & -0.65 \\
\hline Wage & -43.8 & 3.2 & -14.41 & 1.02 & -27.9 & 3.9 & -7.81 & 1.02 \\
\hline \multicolumn{9}{|l|}{ Education (Base: Unskilled) } \\
\hline Skilled & -16.8 & 1.3 & -16.98 & 0.41 & 1.5 & 8.1 & 1.03 & 2.15 \\
\hline Highly skilled & -17.6 & 1.6 & -17.75 & 0.50 & -8.4 & -2.9 & -5.94 & -0.76 \\
\hline Education missing & 28.0 & 0.1 & 28.26 & 0.03 & 10.2 & -5.0 & 7.19 & -1.31 \\
\hline \multicolumn{9}{|l|}{ Share in } \\
\hline ME & 42.9 & -3.7 & 19.22 & -1.15 & 31.4 & -3.5 & 10.63 & -0.92 \\
\hline $\mathrm{RE}$ & -39.1 & 3.6 & -15.16 & 1.15 & -22.3 & 4.2 & -6.73 & 1.10 \\
\hline OLF & 2.6 & -2.5 & 0.89 & -0.80 & -6.0 & -4.3 & -1.67 & -1.12 \\
\hline UE & 14.4 & -1.2 & 5.13 & -0.37 & 4.5 & -1.8 & 1.31 & -0.47 \\
\hline \multicolumn{9}{|l|}{ Interaction with Age $>49$ yrs } \\
\hline $50+\times$ Wage & -8.6 & -2.1 & -2.72 & -0.65 & -2.8 & -2.0 & -0.76 & -0.52 \\
\hline $50+\times$ Share of ME & 26.6 & 2.1 & 15.73 & 0.67 & 17.9 & -3.4 & 7.18 & -0.89 \\
\hline $50+\times$ Share of RE & -6.3 & -0.6 & -2.08 & -0.18 & 2.2 & -1.5 & 0.64 & -0.40 \\
\hline $50+\times$ Share of OOLF & 8.2 & 0.7 & 2.99 & 0.21 & -1.1 & -1.6 & -0.33 & -0.44 \\
\hline $50+\times$ Share of UE & 14.6 & 1.1 & 5.99 & 0.36 & 0.7 & 0.1 & 0.20 & 0.03 \\
\hline Nationality & 20.0 & -0.8 & 20.20 & -0.27 & 5.7 & -2.2 & 4.05 & -0.57 \\
\hline \multicolumn{9}{|c|}{ Firm size (Base: $<5$ employees) } \\
\hline 5-9 employees & 9.7 & 0.6 & 9.77 & 0.20 & 7.9 & 1.1 & 5.59 & 0.32 \\
\hline 10-19 employees & 1.3 & 2.2 & 1.26 & 0.70 & 5.5 & 1.1 & 3.88 & 0.28 \\
\hline 20-49 employees & -9.6 & -1.0 & -9.66 & -0.32 & -5.6 & 3.0 & -3.92 & 0.83 \\
\hline 50-199 employees & -6.0 & -0.5 & -6.05 & -0.16 & -6.2 & 0.9 & -4.39 & 0.23 \\
\hline $200+$ employees & -11.3 & -4.6 & -11.45 & -1.45 & -16.8 & -5.7 & -11.84 & -1.51 \\
\hline \multicolumn{9}{|c|}{ Cohort dummies (Base: Cohort 1) } \\
\hline Cohort 2 & 6.4 & -3.3 & 6.50 & -1.03 & 3.1 & -2.1 & 2.17 & -0.55 \\
\hline Cohort 3 & 2.5 & 4.3 & 2.48 & 1.37 & 3.2 & 0.4 & 2.25 & 0.10 \\
\hline Cohort 4 & -11.5 & 2.1 & -11.61 & 0.67 & -2.4 & 2.0 & -1.67 & 0.54 \\
\hline \multicolumn{9}{|l|}{ Industries (Base: Agriculture) } \\
\hline Manufacturing & -10.7 & -2.9 & -10.83 & -0.92 & -2.6 & 0.8 & -1.86 & 0.21 \\
\hline Construction & -9.1 & 4.5 & -9.17 & 1.43 & 0.8 & 4.8 & 0.58 & 1.31 \\
\hline Trade & 1.7 & -3.5 & 1.71 & -1.08 & 3.3 & -0.2 & 2.31 & -0.07 \\
\hline Transportation & 16.6 & 0.9 & 16.75 & 0.27 & 6.3 & -1.3 & 4.46 & -0.33 \\
\hline Business services & -4.1 & 0.1 & -4.13 & 0.02 & 2.4 & -0.4 & 1.69 & -0.12 \\
\hline Personal services & 15.3 & -0.9 & 15.42 & -0.29 & 9.0 & -0.3 & 6.32 & -0.06 \\
\hline Public services & -6.1 & -0.0 & -6.19 & -0.01 & -13.1 & -5.5 & -9.23 & -1.45 \\
\hline \multicolumn{9}{|c|}{ Occupational status (Base: Apprentice) } \\
\hline Worker & 5.4 & 1.3 & 5.467 & 0.40 & 0.6 & -2.1 & 0.41 & -0.56 \\
\hline Craftsman & -18.0 & 4.4 & -18.19 & 1.41 & -7.3 & 6.0 & -5.13 & 1.61 \\
\hline Appointee/Clerk/Employee & -23.1 & -3.0 & -23.31 & -0.93 & -13.2 & -2.4 & -9.29 & -0.63 \\
\hline Part-time worker & 40.9 & -3.1 & 41.27 & -0.97 & 23.3 & -1.7 & 16.40 & -0.44 \\
\hline
\end{tabular}

Note: For definition of the Standardised Bias (SB) and the t-test, see text. Description of variables are in Table A1 in the Appendix.

Source: Own calculations based on the EP-FEA data.

\subsection{Employment effects}

The estimated average employment effects of taking up ME in the reference period are summarized in Table 4, where we distinguish between three outcome variables: regular employment, ME and unemployment. The estimated average treatment effects are reported for our sample of all men living in eastern and western Germany, respectively, as well as for those aged 50 or older and for those with monthly earnings below the threshold of 166 Euros defined by the unemployment benefit system. Employment effects are measured as differences in days per year. ${ }^{13}$

${ }^{13}$ We calculate standard errors of estimated average treatment effects using the bootstrap method as described in e.g. Efron and Tibshirani (1986) on the basis of 100 repetitions. In a recent paper, Abadie and Imbens (2006) show that for nearest-neighbour 
Table 4

\section{Average employment effects (in days per year)}

\begin{tabular}{|c|c|c|c|c|c|c|}
\hline & \multicolumn{3}{|c|}{ Western Germany } & \multicolumn{3}{|c|}{ Eastern Germany } \\
\hline & All & $(50+)$ & (<166 Euros) & All & $(50+)$ & (<166 Euros) \\
\hline \multirow{2}{*}{ Regular employment } & -0.77 & -9.96 & -0.59 & 8.92 & -1.99 & 11.18 \\
\hline & (4.82) & $(9.67)$ & (6.41) & (5.62) & (11.49) & $(6.80)$ \\
\hline \multirow{2}{*}{ Marginal employment } & $89.90^{\star \star \star}$ & $166.30^{\star \star \star}$ & $90.16^{\star \star \star}$ & $70.35^{\star \star \star}$ & $142.88^{\star \star \star}$ & $68.25^{\star \star \star}$ \\
\hline & (3.49) & (10.96) & (5.52) & $(4.70)$ & (12.50) & $(4.80)$ \\
\hline \multirow{2}{*}{ Unemployment } & $-89.72^{\star \star *}$ & $-156.51^{\star \star *}$ & $-90.23^{\star \star \star}$ & $-80.55^{\star \star *}$ & $-141.81^{\star * *}$ & $-80.65^{\star \star \star}$ \\
\hline & $(4.80)$ & (11.19) & (6.59) & $(6.34)$ & (12.61) & $(7.70)$ \\
\hline
\end{tabular}

Notes: Bootstrapped standard errors in parentheses are calculated following Efron and Tibshirani (1986) on the basis of 100 repetitions. *, **, *** indicate statistical significance at the usual levels of $10 \%, 5 \%$ and $1 \%$ respectively.

As the first line in Table 4 shows, time spent in regular employment within the observation period does not differ significantly between the treatment and the control group. This holds, on average, for the whole treated population in both western and eastern Germany as well as for older people and for those with monthly earnings below 166 Euros.

As for the other two outcome variables, the estimated average treatment effects more or less compensate each other: in western Germany time spent in $\mathrm{ME}$ within the observation period is about 90 days per year longer, on average, and unemployment duration is shorter by the same number of days in the treatment group. Given that the outcome period lasts at least 3 years, this means a total reduction in unemployment duration of roughly 9 months.

Although time spent in ME and in unemployment more or less compensate each other for the older treatment group as well, the estimated effects are almost twice as large as those obtained for the treatment group as a whole: taking up ME reduces unemployment duration in the outcome period for older people by 156 (142) days per year in western (eastern) Germany, with corresponding increases in time spent in ME. For the whole outcome period, this amounts to a reduction in the total duration of unemployment of about 1.3 years.

Regarding ME with earnings of less than 166 Euros, estimated treatment effects hardly deviate from the average effects. Our results thus do not support the popular view that $\mathrm{ME}$ is just a means to supplement

matching with replacement and one or possibly a few neighbours bootstrapping does not yield valid standard errors for the estimated ATT. We cannot rule out that these results may also apply to our application, although we employ six nearest neighbours in the first step of our matching procedure. unemployment benefits thereby prolonging unemployment and reducing incentives to take up regular employment. Since the estimation results of the full and the restricted samples differ little, in the following we only discuss the estimation results for the whole sample.

Figure 3 shows the dynamic treatment effects for the three (un)employment outcome variables measured as absolute difference in days in each quarter of the outcome period. Regarding regular employment, the estimated treatment effects are virtually zero throughout, and this holds for both western and eastern Germany as well as for older people in both regions. If anything, regular employment in the treatment group seems to be increasing in time relative to the respective control group, but in each quarter the difference is very small and not statistically significantly different from zero.

The estimated zero treatment effects reported in Table 4 do not result from a dynamic pattern with, for example, initially less time spent in regular employment by the treatment group relative to the control group being later compensated for by relatively more time spent in regular employment by the former group. Thus, referring to the question asked in the title of our paper, ME does not seem to act as a stepping stone to regular employment.

However, nor is ME a dead end, as the pattern of the dynamic treatment effects for the ME and the unemployment outcome variables in the middle panel of Figure 3 shows: the average ME treatment effect in western (eastern) Germany, i.e. the difference in time spent in ME by the treatment and the control group, declines from about 35 (30) days per quarter at the beginning of the outcome period to 10 (8) days after 12 quarters. For older people both in western and eastern Germany, the decline of 


\section{Figure 3 \\ Dynamic (un)employment effects}
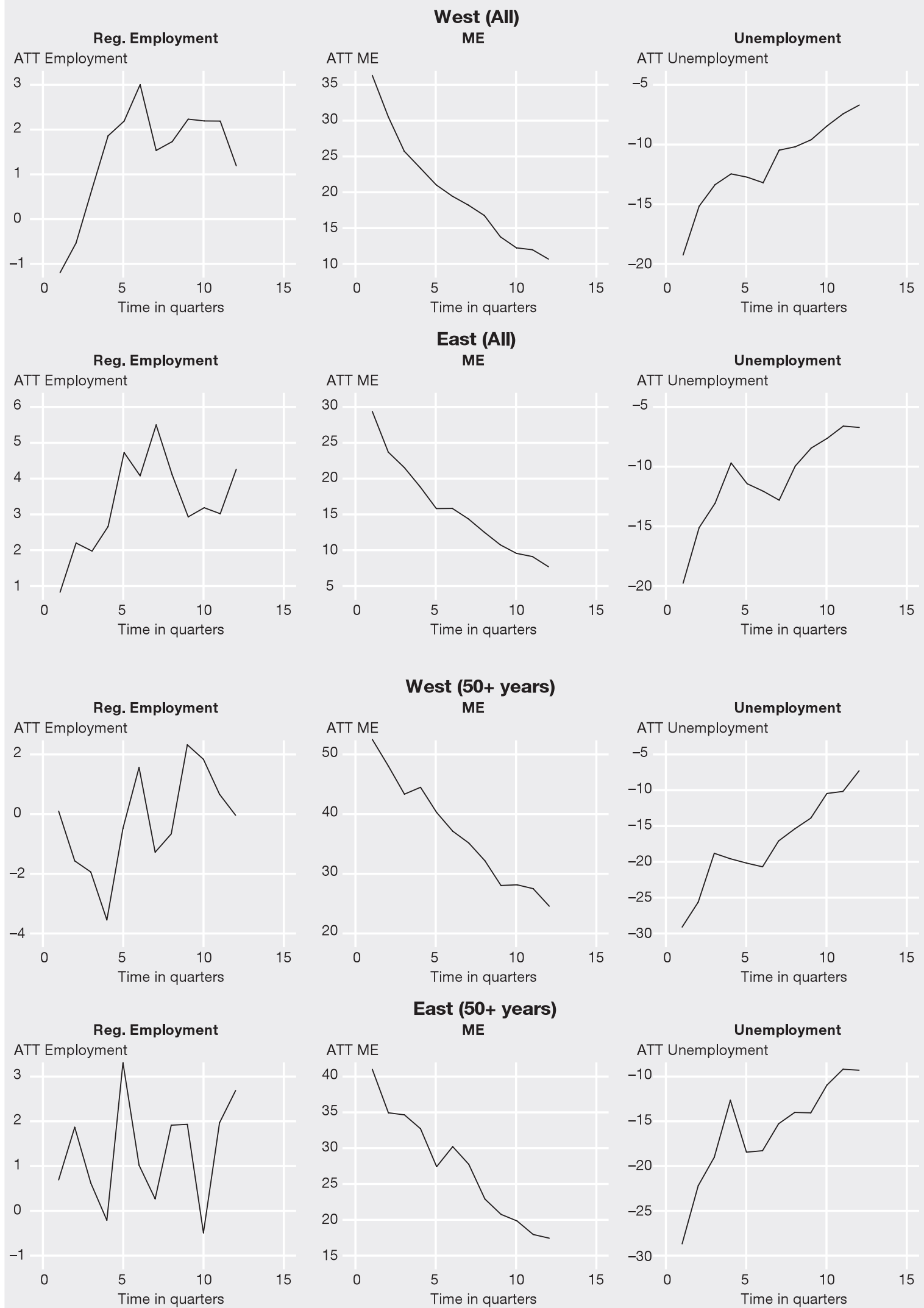
treatment effects is similar in relative terms, although their level is substantially higher, corresponding to the larger absolute average treatment effects documented in Table 4. Thus, there does not seem to be a "lock-in" effect regarding ME, as has been observed for other labour market programmes. This is also confirmed by the dynamic pattern of the treatment effects regarding regular employment in Figure 3 Column 1.

For the unemployment outcome variable, Figure 3 shows roughly the opposite pattern of dynamic treatment effects: the difference in unemployment between the treatment and the control group declines rapidly in the first few quarters of the outcome period, then increases again (in absolute terms), or at least does not further decline, for a couple of quarters, and subsequently continues to decline until it reaches only a few days at the end of the outcome period. There is little difference here between the estimated average treatment effects of the two regions and also of the treatment group as a whole and the sub-sample of older people. Since the dynamic treatment effects plotted in Figure 3 measure differences in the outcome variables, they are not informative about the question whether these effects are driven by changes in a particular outcome variable in the treatment group or in the control group, or both. Furthermore, the number of days spent in a particular labour market state in any given quarter by both of the groups can be split up into the share of people with at least one day spent in each of these states and the average number of days spent in each state. Figure A2 in the Appendix plots the shares of people in both the treatment and the control groups with zero days spent in a particular state in a given quarter.

For the treatment group as a whole, the share of people with zero days in ME increases substantially over time, whereas this share declines slightly but steadily in the respective control group. This shows that the pattern of the dynamic treatment effects for the ME outcome variable depicted in Figure 3 is mainly driven by the increasing share of people in the treatment group who terminate ME, although the slightly increasing share of people who took up ME during the outcome period has also contributed to the adjustment process.

The opposite dynamic pattern is observed for the unemployment outcome variable: the share of people with zero days of unemployment in the treatment group remains more or less at its initial level, whereas for the respective control group this share strongly increases over time reaching a similar level to the treatment group at the end of the observation period. This dynamic pattern strongly indicates that the unemployment rates in the two groups converge in the long run and that the effects of taking up ME on unemployment are only transitory. Still, these transitory effects are quite substantial cumulated over the observed outcome period of three years.

As mentioned above, an increasing share of people whom we included in our control group because they did not take up ME in the pre-specified risk period actually took up ME during the outcome period. As a sensitivity check, we excluded people from the control group who changed treatment status during the outcome period, i.e. moved from unemployment or regular employment into $\mathrm{ME}$, and re-estimated the treatment effects for the (un)employment outcome variables. The estimation results, summarized in the upper part of Table A3 in the Appendix, show that our conclusions derived from Table 4 do not change qualitatively if we use this modified control group. Although the treatment effects estimated for the ME and unemployment outcome variables increase in absolute terms, the magnitude of these changes is rather small. For example, for the unemployment outcome variable the estimated average effect for the western German treatment group as a whole increases from about -90 days (with an estimated s.e. of 4.8) to -107 days (s. e. $=5.4)$, hardly a statistically significant change. Of course, estimates of these 'conditional' treatment effects, conditional on not taking up ME in the risk period may induce selection bias. Furthermore, even if these conditional treatment effects were unbiased, their interpretation is difficult since they do not refer to a clearly defined reference group. However, since the exclusion of people who changed treatment status from the control group leaves our estimation results virtually unchanged, we find no evidence indicating the presence of selection effects.

\subsection{Earnings effects}

The estimated earnings effects of taking up ME in the reference period measured as differences between the monthly earnings of the treatment and the control group are summarized in Table 5 for all treated persons and for those aged 50 or older. The control group is defined as in the main analysis of employment effects above, i.e. including those who took up ME after the risk period.

The first row of Table 5 shows that, conditional on either ME or regular employment, the average monthly gross earnings of the treatment group were much lower than those of the control group during 
Table 5

\section{Average earnings effects}

\begin{tabular}{|l|c|c|c|c|}
\hline \multirow{2}{*}{} & \multicolumn{2}{|c|}{ Western Germany } & \multicolumn{2}{c|}{ Eastern Germany } \\
\cline { 2 - 5 } & All & $\mathbf{( 5 0 + )}$ & All & (50+) \\
\hline Average effects on earnings (monthly gross earnings in Euros) \\
\hline \multirow{2}{*}{ Employment (regular and marginal) } & $-473.39^{\star \star \star}$ & $-742.55^{\star \star \star}$ & $-303.09^{\star \star \star}$ & $-492.38^{\star \star \star}$ \\
\cline { 2 - 5 } & $(36.03)$ & $(120.42)$ & $(33.63)$ & $(81.49)$ \\
\hline \multirow{2}{*}{ Regular employment only } & $-166.47^{\star \star \star}$ & -109.91 & $-58.09^{\star}$ & -31.25 \\
\cline { 2 - 5 } & $(38.49)$ & $(149.56)$ & $(32.76)$ & $(97.01)$ \\
\hline Cumulative effects (Earnings in Euros per year) & 189.37 & -642.83 & 732.87 & 779.11 \\
\hline
\end{tabular}

Bootstrapped standard errors in parentheses, see Efron and Tibshirani (1986), were calculated on the basis of 100 repetitions.

*, **, *** indicate statistical significance at the usual levels of $10 \%, 5 \%$ and $1 \%$ respectively.

the outcome period; the (negative) average treatment effect amounts to about 470 (300) Euros in western (eastern) Germany. In both regions, the treatment effects on earnings are particularly strong for older men, amounting to about 740 Euros per month in western Germany and to 490 Euros in the eastern. Since these effects are conditional on being either in ME or in regular employment, the large negative earnings differential virtually arises by definition of ME. What is more interesting is the estimated treatment effect on earnings in regular employment. This effect amounts to about 166 (60) Euros in western (eastern) Germany for the treatment group as a whole, but is not statistically significant for older people. ${ }^{14}$ Regional differences in estimated treatment effects on earnings are probably related to the still much lower level of wages in regular employment in the eastern German labour market.

Since we know from the previous section that the treatment group spends roughly the same time in regular employment as the control group, but less time in unemployment, one would expect earnings cumulated over the outcome period to be higher for the treatment group, on average. As the last row of Table 5 shows, this conjecture is indeed true on average, although the estimated cumulated earnings effect differs substantially by region and age: whereas it amounts to about 730 Euros per year in eastern Germany, where it differs little by age, the cumulative average earnings effect is less than 200 Euros in the western, and even slightly negative for older people. ${ }^{15}$ Thus, this group's lower unemploy-

\footnotetext{
${ }^{14}$ We obtain qualitatively similar results when people who changed treatment status during the outcome period are excluded from the control group; see the estimation results in the lower part of Table (A3) in the Appendix.

${ }^{15}$ We have used the estimated negative earnings differential in regular employment for older people, although it is not statistically significant.
}

ment in the outcome period does not fully compensate for the negative earnings differential in either form of employment help by the treatment group during the outcome period, if this only amounts to a fairly small negative cumulative earnings effect of about 640 Euros per year.

\section{Conclusion}

In this paper we have investigated, for the German economy, whether marginal employment (ME) acts as a stepping stone into regular employment for unemployed men or instead leads to dead-end jobs with little pay and a large degree of job insecurity, as critics claim. Using newly available register data from the Federal Employment Agency covering the period 1998-2005 and statistical matching techniques, we have analysed differences in various labour market outcome variables between a treatment group of previously unemployed men who took up $\mathrm{ME}$ at the beginning of their unemployment spell and a control group of people who did not.

Our empirical results show that although ME does not significantly increase the treatment group's chance of gaining regular employment during an outcome period of at least three years, it reduces future unemployment and, on average, slightly increases the cumulated future earnings of the treatment group relative to the control group. The treatment effect on future unemployment is substantial in both western and eastern Germany: during the three-year outcome period the total duration of unemployment experienced by the treatment group is reduced by about 9 months on average, relative to the control group. For older people, unemployment treatment effects are almost twice as large as those obtained for the treatment group as a whole, amounting to a reduction in the total duration of unemployment of about 1.3 years during the whole 
outcome period. Still, the cumulative treatment effect on earnings for older men is slightly negative in western Germany and only modestly positive in eastern Germany. From a policy perspective, our evaluation results suggest that exemption from social security contributions may be effective in reducing unemployment, especially regarding older men, who have been an important target group of recent 'active' labour market policy in Germany, see e.g. Haan and Steiner (2008). However, the dynamic pattern of the estimated treatment effects indicates that the impact of taking up ME on unemployment is to a large extent only transitory. Thus, ME might not be an effective labour market policy, especially for younger workers.

These results seem robust with respect to our definition of the control group and to the inclusion of $\mathrm{ME}$ with earnings below the maximum threshold for receiving unemployment benefits. Excluding people from the control group who changed treatment status during the outcome period, i.e. moved from unemployment or regular employment into ME, did not significantly change the estimated treatment effects for the (un)employment outcome variables. We also found no evidence for the hypothesis that ME is just a means to supplement unemployment benefits thereby prolonging unemployment and reducing incentives to take up regular employment. However, given the limitations of the statistical matching approach, we cannot rule out substitution effects between ME, which is exempted from social security contributions, and regular employment. In fact, recent empirical evidence for Germany suggests that $\mathrm{ME}$ and regular employment are substitutes in production, even if the size of the substitution elasticity is not very large for men in Germany (see Freier and Steiner 2007). Given this result and the fairly small share of men working part-time, substitution effects seem negligible for them. However, they might still be of substantial size for women. Thus, analysing the labour market effects of marginal employment for women would require a more general empirical methodology which also would have to take into account the potential substitution effects between part-time and marginal employment.

\section{References}

Abadie, A./Imbens, G.W. (2006): On the failure of the bootstrap for matching estimators, NBER Technical Working Paper, No. 325, NBER, Cambridge.

Abbring, J. H./van der Berg, G. J. (2003): The Nonparametric Identification of Treatment Effects in Duration Models, Econometrica, Vol. 71 (5), pp. 1491-1517.
Arntz, N./Feil, M./Spermann, A. (2003): Die Arbeitsangebotseffekte der neuen Mini- und Midi-Jobs, Mitteilungen aus der Arbeitsmarkt- und Berufsforschung, 36.

Bofinger, P./Dietz, M./Genders, S./Walwei, U. (2006): Vorrang für das reguläre Arbeitsverhältnis: Ein Konzept für Existenz sichernde Beschäftigung im Niedriglohnbereich. Gutachten für das Sächsische Ministerium für Wirtschaft und Arbeit (SWMA), Dresden.

Böheim, R./Weber, A. (2006): The effects of marginal employment on subsequent labour market outcomes, IZA Discussion Paper, No. 2221, July, Bonn.

Caliendo, M./Kopeinig, S. (2008): Some practical guidance for the implementation of propensity score matching, Journal of Economic Surveys, Vol. 22 (1), 31-72.

Caliendo, M./Wrohlich, K. (2008): Evaluating the German 'Mini-Jobs' Reform Using a True Natural Experiment, Applied Economics, (forthcoming 2008).

Efron, B./Tibshirani, R. (1986): Bootstrap Methods for Standard Errors, Confidence Intervals, and Other Measures of Statistical Accuracy, Statistical Science, Vol. 1, Issue 1, pp. 54-75.

Fertig, M./Kluve, J. (2006): Alternative Beschäftigunsformen in Deutschland: Effekte der Neuregelung von Zeitarbeit, Minijobs und Midijobs, Vierteljahreshefte zur Wirtschaftsforschung, 75 (3), pp. 97-117.

Fitzenberger, B./Osikominu, A./Völter, R. (2006): Get Training or Wait? Long Run Employment Effects of Training Programs for the Unemployed in Germany, ZEW Discussionpaper, Mannheim.

Freier, R./Steiner, V. (2007): 'Marginal Employment' and the demand for heterogeneous labour: Empirical evidence from a multi-factor labour demand model for Germany, IZA Discussion Paper, No. 2577, January, Bonn.

Gerfin, M./Lechner, M. (2002): A Microeconometric Evaluation of Active Labour Market Policy in Switzerland, The Economic Journal, Vol. 112, Issue 482, pp. 854-893.

Haan, P./Steiner, V. (2006): Making Work Pay for the Elderly Unemployed - Evaluating alternative policy reforms for Germany, Finanzarchiv - Public Finance Analysis (in press).

Heckman, J.J./Ichimura, H./Smith, J./Todd, P. (1998): Characterizing Selection Bias Using Experimental Data, Econometrica, 66 (5), pp. 1017-1098.

Heckman, J. J./LaLonde, R. J./Smith, J. A. (1999): The economics and econometrics of active labor market programs, in Ashenfelter, O. and Card, D. (eds.): Handbook of Labor Economics, Vol. III A, chapter 31, pp. $1865-$ 2097.

Heckman, J. J./Robb, R. (1985): Alternative Methods for Evaluating the Impact of Interventions, in Heckman, J. J. and Sniger, B. (eds.): Longitudinal Analysis of Labour Market Data, Cambridge University Press. 
Hujer, R./Maurer, K.-O./Wellner, M. (1997): The Impact of Training on Unemployment Duration in West Germany: Combining a Discrete Hazard Rate Model with Matching Techniques, Frankfurter Volkswirtschaftliche Diskussionsbeiträge, No. 94, Johann Wolfgang Goethe-University, Frankfurt/Main.

Ichino, A./Mealli, F./Nannicini, T. (2006): From temporary help jobs to permanent employment: What can we learn from matching estimators and their sensitivity?, IZA Discussion Paper, No. 2149, Bonn.

Kraus, F./Puhani, P. A./Steiner, V. (1999): Employment Effects of Publicly Financed Training Programs - The East German Experience, Jahrbücher für Nationalökonomie und Statistik, Band 219/1+2, 1999, pp. 216-248.

Lechner, M. (1999): Earnings and employment effects of continuous off-the-job training in East Germany after unification. Journal of Business and Economic Statistics, 17 (1), pp. $74-90$

Meinken, H./Koch, H. (2005): BA-Beschäftigtenpanel 1998-2002, Codebuch, Bundesagentur für Arbeit, Nürnberg.

Müller, K.-U. (2007): Individual and regional determinants of receiving unemployment benefit sanctions in Germany, Wirt Sozialstat Archiv, 1, pp. 275-286.

Rosenbaum, P./Rubin, D. (1985): Constructing a Control Group Using Multivariate Matched Sampling Methods that Incorporate the Propensity Score, The American Statistican, 39 (1), pp. 33-38.
Rudolph, H. (1998): Geringfügige Beschäftigung mit steigender Tendenz. Erhebungskonzepte, Ergebnisse und Interpretationsprobleme der verfügbaren Datenquellen, IAB Werkstattbericht, 9, Nuremberg.

Schöb, R./Weimann, J. (2004): Arbeit ist machbar. Die neue Beschäftigungsformel. Verlag Janos Stekovics, Dössel.

Schupp, J./Schwarze, J./Wagner, G. (1998): Methodische Probleme und neue empirische Ergebnisse für die Messung geringfügiger Beschäftigung, in: J. Schupp, F. Büchel, and R. Habich (eds.): Arbeitsmarktstatistik zwischen Fiktion und Realität, edition sigma, Berlin.

Schupp, J./Birkner, E. (2004): Kleine Beschäftigungsverhältnisse: Kein Jobwunder, DIW Wochenbericht, No. 34/2004, pp. 467-497.

Sianesi, B. (2004): An Evaluation of the Active Labour Market Programmes in Sweden. The Review of Economics and Statistics, 86 (1), pp. 133-155.

Steiner, V./Wrohlich K. (2005): Work Incentives and Labor Supply Effects of the 'Mini-Jobs Reform' in Germany, Empirica, 32, pp. 91-116.

Steiner, V. (2006): Subventionierung von Beschäftigung im Niedriglohnbereich - Ein Ausweg aus der Beschäftigungskrise?, Wirtschaftspolitische Blätter, 53 (2), pp. 213-228.

Ziemendorff, J. (2006): The German 'Mini-Job' Reform: Why the Job Miracle is Not a Miracle, Unpublished Master Thesis, Humboldt-Universität zu Berlin. 


\section{Appendix}

Table A1

\section{Descriptive statistics}

\begin{tabular}{|c|c|c|c|c|c|c|c|c|}
\hline & \multicolumn{4}{|c|}{ West } & \multicolumn{4}{|c|}{ East } \\
\hline & \multicolumn{2}{|c|}{ Control } & \multicolumn{2}{|c|}{ Treated } & \multicolumn{2}{|c|}{ Control } & \multicolumn{2}{|c|}{ Treated } \\
\hline & Mean & Std & Mean & Std & Mean & Std & Mean & Std \\
\hline $30<$ Age $<50$ & 0.458 & 0.248 & 0.482 & 0.250 & 0.459 & 0.248 & 0.493 & 0.250 \\
\hline Age $>49$ & 0.160 & 0.135 & 0.191 & 0.155 & 0.199 & 0.159 & 0.224 & 0.174 \\
\hline Wage & 1721.0 & 1037.8 & 1290.3 & 924.4 & 1272.2 & 750.0 & 1069.3 & 705.1 \\
\hline \multicolumn{9}{|l|}{ Education (Base: Unskilled) } \\
\hline Skilled & 0.522 & 0.250 & 0.438 & 0.246 & 0.650 & 0.227 & 0.657 & 0.225 \\
\hline Highly skilled & 0.035 & 0.034 & 0.009 & 0.009 & 0.038 & 0.036 & 0.023 & 0.023 \\
\hline Education missing & 0.167 & 0.139 & 0.283 & 0.203 & 0.158 & 0.133 & 0.196 & 0.158 \\
\hline \multicolumn{9}{|l|}{ Share in } \\
\hline Marginal Employment (ME) & 0.037 & 0.146 & 0.122 & 0.239 & 0.035 & 0.137 & 0.088 & 0.194 \\
\hline Regular Employment (RE) & 0.771 & 0.278 & 0.647 & 0.354 & 0.724 & 0.290 & 0.656 & 0.326 \\
\hline Out of the labour force (OLF) & 0.108 & 0.177 & 0.113 & 0.171 & 0.096 & 0.161 & 0.087 & 0.150 \\
\hline Unemployment (UE) & 0.213 & 0.293 & 0.257 & 0.315 & 0.268 & 0.315 & 0.283 & 0.325 \\
\hline \multicolumn{9}{|l|}{ Interaction with Age $>49$} \\
\hline $50+\times$ Wage & 336.7 & 928.3 & 264.3 & 752.2 & 289.0 & 687.1 & 270.9 & 614.9 \\
\hline $50+\times$ Share in ME & 0.005 & 0.060 & 0.037 & 0.157 & 0.005 & 0.055 & 0.021 & 0.107 \\
\hline $50+\times$ Share in $\mathrm{RE}$ & 0.131 & 0.320 & 0.112 & 0.292 & 0.147 & 0.319 & 0.154 & 0.321 \\
\hline $50+\times$ Share in OOLF & 0.010 & 0.057 & 0.015 & 0.064 & 0.016 & 0.067 & 0.015 & 0.07 \\
\hline $50+x$ Share in UE & 0.026 & 0.123 & 0.048 & 0.174 & 0.050 & 0.166 & 0.051 & 0.163 \\
\hline Nationality & 0.190 & 0.154 & 0.275 & 0.199 & 0.040 & 0.039 & 0.052 & 0.049 \\
\hline \multicolumn{9}{|l|}{ Firm size (Base: $<5$ employees) } \\
\hline 5-9 employees & 0.129 & 0.112 & 0.163 & 0.136 & 0.126 & 0.110 & 0.153 & 0.130 \\
\hline 10-19 employees & 0.146 & 0.125 & 0.150 & 0.128 & 0.137 & 0.118 & 0.156 & 0.132 \\
\hline 20-49 employees & 0.181 & 0.148 & 0.146 & 0.124 & 0.194 & 0.156 & 0.172 & 0.142 \\
\hline 50-199 employees & 0.221 & 0.172 & 0.197 & 0.158 & 0.229 & 0.176 & 0.203 & 0.162 \\
\hline $200+$ employees & 0.189 & 0.153 & 0.146 & 0.125 & 0.186 & 0.152 & 0.125 & 0.110 \\
\hline \multicolumn{9}{|c|}{ Cohort dummies (Base: Cohort 1) } \\
\hline Cohort 2 & 0.216 & 0.169 & 0.243 & 0.184 & 0.220 & 0.172 & 0.233 & 0.179 \\
\hline Cohort 3 & 0.308 & 0.213 & 0.320 & 0.217 & 0.288 & 0.205 & 0.303 & 0.211 \\
\hline Cohort 4 & 0.282 & 0.202 & 0.232 & 0.178 & 0.295 & 0.208 & 0.284 & 0.203 \\
\hline \multicolumn{9}{|l|}{ Industries (Base: Agriculture) } \\
\hline Manufacturing & 0.219 & 0.171 & 0.176 & 0.145 & 0.106 & 0.094 & 0.098 & 0.088 \\
\hline Construction & 0.211 & 0.166 & 0.175 & 0.144 & 0.306 & 0.212 & 0.310 & 0.214 \\
\hline Trade & 0.135 & 0.117 & 0.141 & 0.121 & 0.079 & 0.072 & 0.088 & 0.080 \\
\hline Transportation & 0.073 & 0.068 & 0.122 & 0.107 & 0.055 & 0.052 & 0.070 & 0.065 \\
\hline Business services & 0.175 & 0.144 & 0.160 & 0.134 & 0.144 & 0.123 & 0.152 & 0.129 \\
\hline Personal services & 0.078 & 0.072 & 0.124 & 0.109 & 0.070 & 0.065 & 0.094 & 0.085 \\
\hline Public services & 0.067 & 0.062 & 0.052 & 0.049 & 0.159 & 0.134 & 0.114 & 0.101 \\
\hline \multicolumn{9}{|c|}{ Occupational status (Base: Apprentice) } \\
\hline Worker & 0.372 & 0.234 & 0.399 & 0.240 & 0.211 & 0.166 & 0.213 & 0.168 \\
\hline Craftsman & 0.299 & 0.209 & 0.220 & 0.172 & 0.425 & 0.244 & 0.390 & 0.238 \\
\hline Appointee/Clerk/Employee & 0.174 & 0.144 & 0.096 & 0.087 & 0.126 & 0.110 & 0.085 & 0.078 \\
\hline Part-time worker & 0.094 & 0.085 & 0.244 & 0.185 & 0.166 & 0.138 & 0.261 & 0.193 \\
\hline
\end{tabular}

Source: Own calculations based on the EP-FEA data. 
Table A2

\section{Probit estimates of the propensity scores}

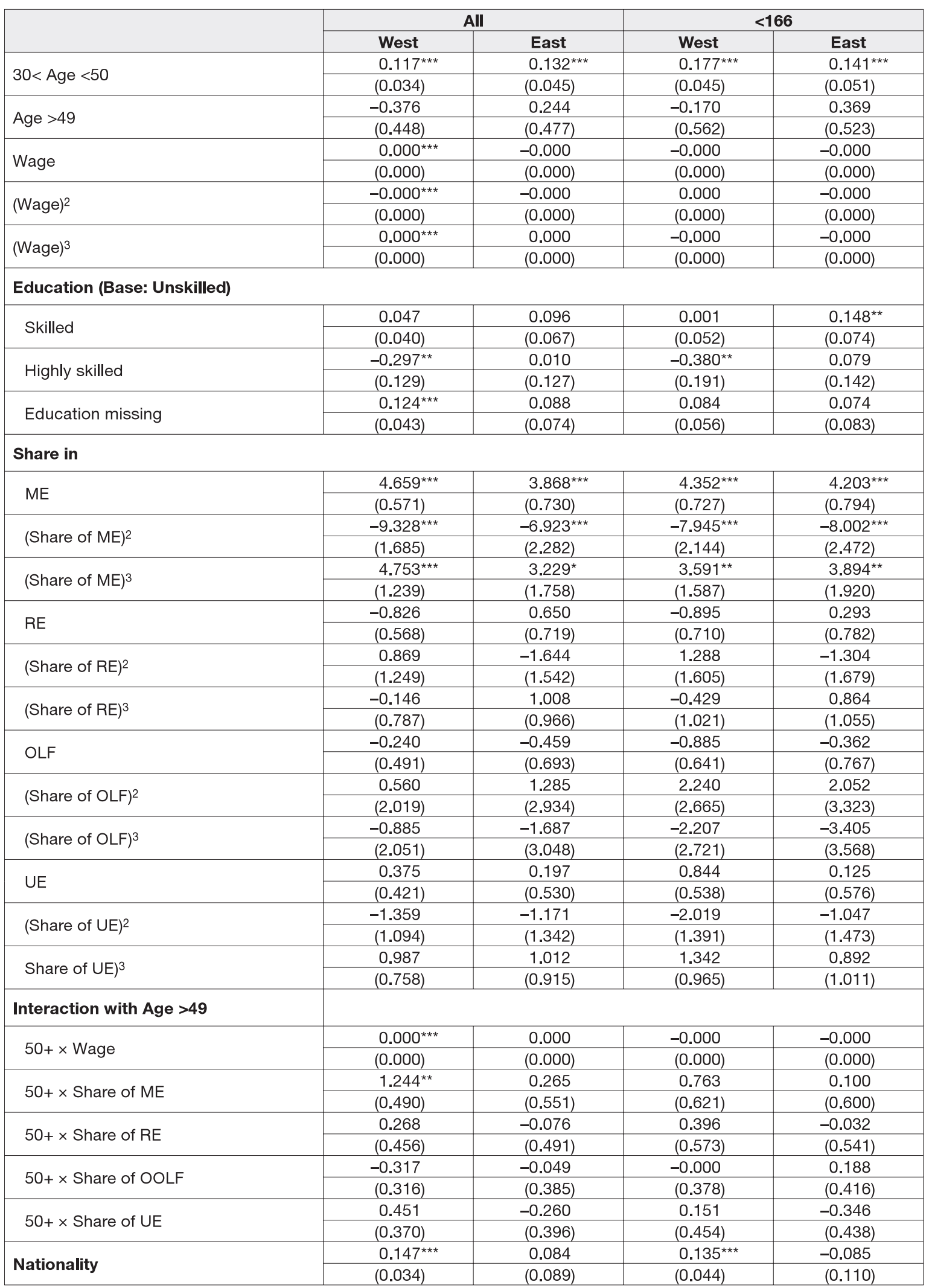


Table A2 (continued)

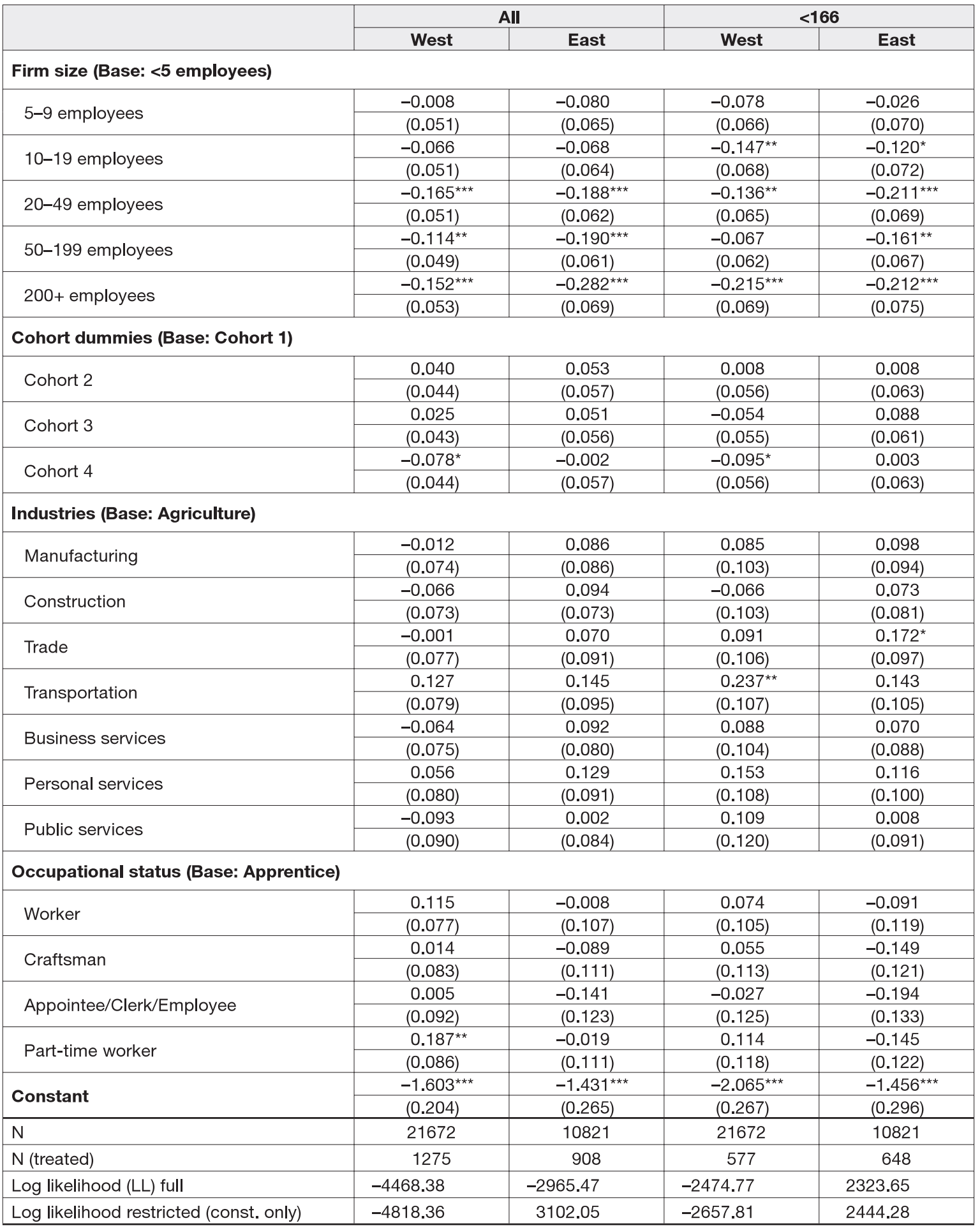


Table A3

\section{Sensitivity analysis - leaving out ME from the control group}

\begin{tabular}{|c|c|c|c|c|}
\hline & \multicolumn{2}{|c|}{ West } & \multicolumn{2}{|c|}{ East } \\
\hline & All & $(50+)$ & All & $(50+)$ \\
\hline \multirow{2}{*}{ Reg. employment (in days per year) } & $-8.77^{\star}$ & -11.83 & 0.06 & -3.93 \\
\hline & $(5.33)$ & (12.32) & $(6.25)$ & $(11.87)$ \\
\hline \multirow{2}{*}{ Marginal employment (in days per year) } & $115.12^{\star * *}$ & $206.07^{* * *}$ & $93.55^{\star * *}$ & $171.32^{* * *}$ \\
\hline & $(3.39)$ & $(9.29)$ & $(4.37)$ & $(12.17)$ \\
\hline \multirow{2}{*}{ Unemployment (in days per year) } & $-107.35^{\star \star \star}$ & $-194.67^{\star * \star}$ & $-95.48^{\star \star \star}$ & $-168.77^{\star \star \star}$ \\
\hline & $(5.43)$ & $(11.24)$ & $(6.51)$ & $(14.02)$ \\
\hline \multicolumn{5}{|c|}{ Average effects on earnings (monthly earnings in Euros) } \\
\hline \multirow{2}{*}{ Employment (reg. and marg.) } & $-771.85^{\star \star \star}$ & $-1230.30^{\star \star \star}$ & $-552.56^{\star \star \star}$ & $-783.77^{\star \star \star}$ \\
\hline & $(36.37)$ & $(113.40)$ & (36.78) & $(81.67)$ \\
\hline \multirow{2}{*}{ Regular employment only } & $-202.67^{\star \star *}$ & -100.95 & $-76.17^{\star \star \star}$ & -69.35 \\
\hline & $(36.81)$ & (168.63) & $(33.87)$ & (92.58) \\
\hline
\end{tabular}

\section{Figure A1}

\section{Distribution of property scores for treatment and control group}

Distribution of propensitiy score - West

Not in ME

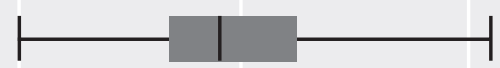

ME

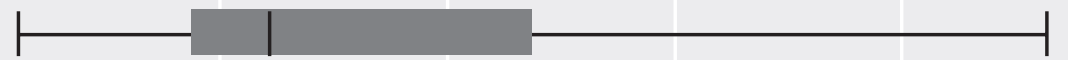

0

excludes outside values

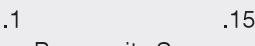

.2

.25

Distribution of propensitiy score - East

Not in ME

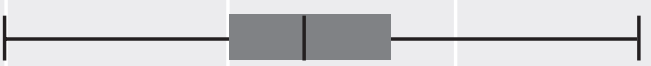

ME

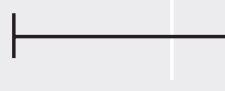

.05

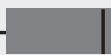

Propensity Score

excludes outside values

15

.25

Note: The width of the rectangular box gives the distance between the 25th and the 75th percentile, the line within the box gives the median. The lines ('whiskers') on both sides of the boxplot indicate the range of one standard deviation to each side respectively. In the graphs,

a few observations with propensity scores outside the indicated range are excluded. 


\section{Figure A2}

Quarterly shares of people with zero days spent in a particular labour market state in the treatment $(M E=1)$ and the control group $(M E=0)$
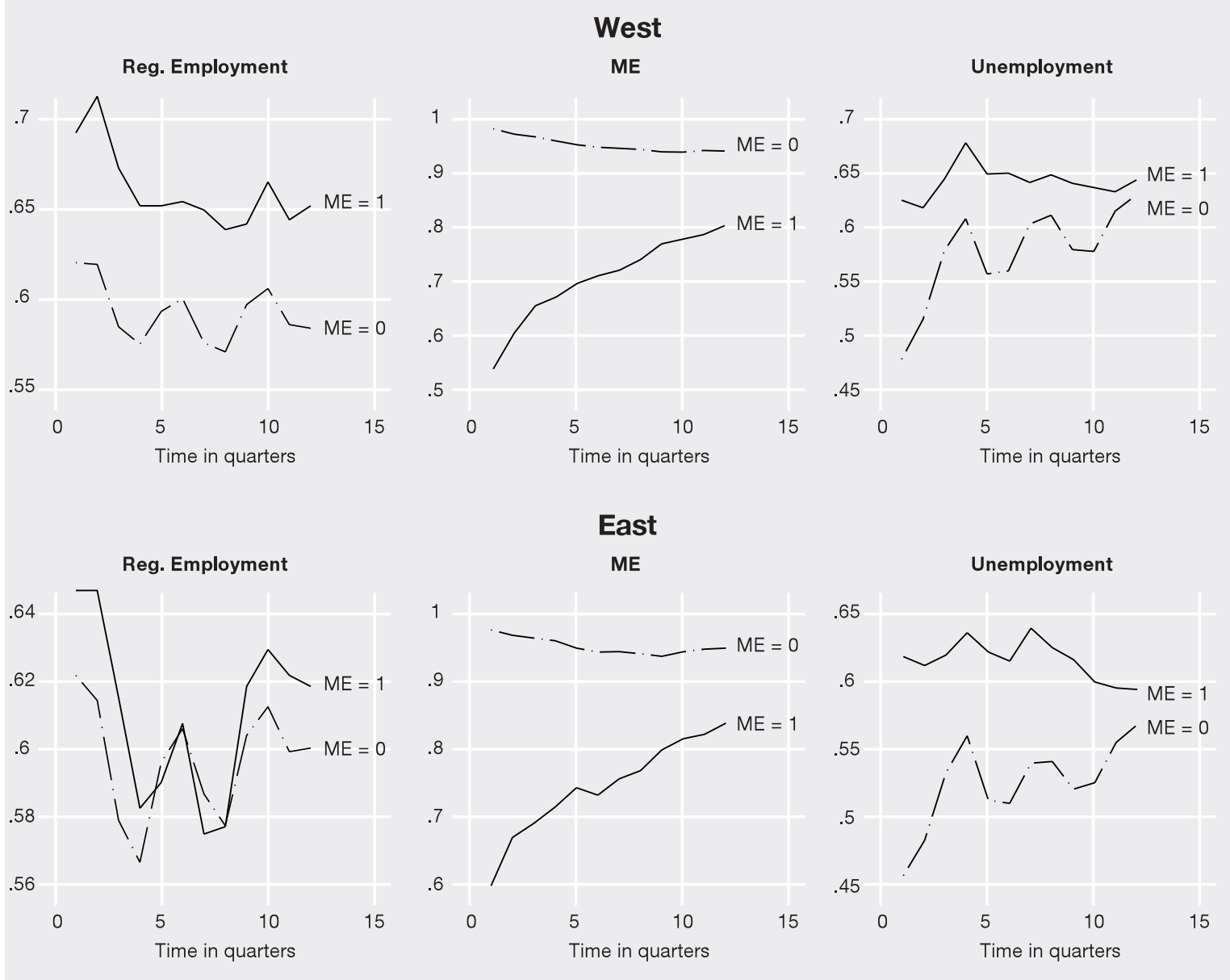